\title{
Two cases of combined anatomical variations: maxillofacial trunk, vertebral, posterior communicating and anterior cerebral atresia, linguofacial and labiomental trunks
}

\author{
M.C. Rusu'10, A.M. Jianu'2, M.D. Monea², A.C. $\| l i e^{3}$ \\ 'Division of Anatomy, Faculty of Dental Medicine, "Carol Davila" University of Medicine and Pharmacy, Bucharest, Romania \\ 2Department of Anatomy, Faculty of Medicine, "Victor Babeş" University of Medicine and Pharmacy, Timişoara, Romania \\ 3Department of Functional Sciences, Discipline of Public Health, Faculty of Medicine, "Victor Babes" University of Medicine \\ and Pharmacy, Timisoara, Romania
}

[Received: 28 November 2020; Accepted: 8 January 2021; Early publication date: 29 January 2021]

\begin{abstract}
Background: Commonly, arterial anatomic variants are reported as single entities. However, different such variants can occur in a single patient.

Materials and methods: During a retrospective study of computed tomography angiograms of 52 adult patients, 2 cases were found with unilateral maxillofacial trunks. In each case different other anatomic variants were documented.

Results: The maxillofacial trunk in the first case was associated with bilateral posterior kinks of the internal carotid artery which passed beyond the transverse processes of the atlas vertebra and indented and displaced the internal jugular veins. Common carotid origins of the superior thyroid arteries were found, as well as a high origin of the contralateral facial artery. In the second case a plethora of variants were associated with a unilateral maxillofacial trunk: 1) direct occipital-vertebral arterial anastomosis; 2) ipsilateral atresia of the distal vertebral artery and of the A1 segment of the anterior cerebral artery; 3) bilateral atresia of posterior communicating arteries; 4) linguofacial and labiomental trunks; 5) terminal trifurcation of the external carotid artery.

Conclusions: The arterial anatomical variants of the head and neck should be carefully documented prior to specific surgical and interventional procedures, as well as for understanding the compensatory anatomical pathways of circulatory insufficiencies. (Folia Morphol 2022; 81, 1: 237-246)
\end{abstract}

Key words: vertebral artery, carotid artery, circle of Willis, maxillary artery, facial artery

\section{INTRODUCTION}

The external (ECA) and the internal (ICA) carotid arteries are the terminal branches of the common carotid artery (CCA), leaving it in the carotid triangle of neck [32], typically at the level of the upper border of the thyroid cartilage.

The ECA further sends off its collateral branches: the superior thyroid artery (StA), lingual artery (LA),

Address for correspondence: M.C. Rusu, MD, PhD (Med.), PhD (Biol.), Dr. Hab., Prof., Division of Anatomy, Faculty of Dental Medicine, "Carol Davila" University of Medicine and Pharmacy, 8 Eroilor Sanitari Blvd., RO-76241, Bucharest, Romania, tel: +40722363705, e-mail: mugurel.rusu@umfcd.ro

This article is available in open access under Creative Common Attribution-Non-Commercial-No Derivatives 4.0 International (CC BY-NC-ND 4.0) license, allowing to download articles and share them with others as long as they credit the authors and the publisher, but without permission to change them in any way or use them commercially. 
facial artery (FA), ascending pharyngeal artery (APA), occipital artery $(O A)$ and posterior auricular artery (PAA). Commonly, the ECA divides terminally into the maxillary (MA) and superficial temporal (STA) arteries. Rarely, the ECA could trifurcate terminally, the third added branch being either the middle meningeal artery (MMA), or the transverse facial artery (TFA) [31].

Different common trunks could result after the fusion of the ECA branches, such as the thyrolingual, linguofacial and thyrolinguofacial trunks $[4,20]$. The maxillofacial trunk (MFT) is an extraordinary arterial variation in man [28]. Although few authors were quoted by Pretterklieber et al. [28] for listing this last arterial variation, they did not provide supportive evidence $[4,15]$. In the online "Illustrated Encyclopedia of Human Anatomic Variation" Bergman et al. [3] documented that the origin of the MA is constant and very rarely it leaves the FA to course upwards into the infratemporal fossa.

The posterior cerebral circulation is supplied by the vertebrobasilar system of arteries. The vertebral arteries (VAs) commonly join in the posterior cranial fossa to form the basilar artery (BA). This later supplies the circle of Willis, as the ICAs also do. Cerebral insufficiencies could result if anatomical variant lead to an incomplete circle of Willis, but they could be compensated by ECA-to-VA anastomoses.

It was therefore aimed at documenting a retrospective lot of computed tomography (CT) angiograms for the MFT variant and whether, or not, other anatomic variations are associated with it.

\section{MATERIALS AND METHODS}

The anatomic variations reported here were found during a retrospective study of $\mathrm{CT}$ angiograms from 52 adult patients, a 68-year-old female patient (case 1) and a 57-year-old male patient (case 2). For the CT studies an iodine radiocontrast agent (Ultravist $370 \mathrm{mg} / \mathrm{mL}$ ) was injected in the brachial vein, followed by $20 \mathrm{~mL}$ saline medium. The CT was performed with a 32-slice scanner (Siemens Multislice Perspective Scanner), using a $0.6 \mathrm{~mm}$ collimation and reconstruction of $0.75 \mathrm{~mm}$ thickness with $50 \%$ overlap for multiplanar and three-dimensional volume rendering technique [31]. The arterial variants were documented with the Horos software. The research was conducted ethically in accordance with The Code of Ethics of the World Medical Association (Declaration of Helsinki). Informed consent for anonymous use of the data with scientific purposes was signed
Table 1. Anatomic variations encountered in the $2 / 52$ cases found with maxillofacial trunks

\begin{tabular}{lcc}
\hline Anatomic variation & Case 1 & Case 2 \\
\hline Maxillofacial trunk & $\mathrm{U}$ & $\mathrm{U}$ \\
ICA folded into the IJV & $\mathrm{B}$ & - \\
CCA origin of the StA & $\mathrm{B}$ & - \\
Os stylo-hyale & $\mathrm{B}$ & - \\
High origin (C2) of the facial artery & $\mathrm{U}$ & - \\
CB origin of the StA & - & $\mathrm{B}$ \\
Os cerato-hyale & - & $\mathrm{B}$ \\
Occipital-to-vertebral arterial anastomosis & - & $\mathrm{U}$ \\
Terminal trifurcation of the ECA & - & $\mathrm{U}$ \\
Aberrant course of the STA & & \\
Aplasia of the distal segment of the VA & - & $\mathrm{U}$ \\
Aplasia of the A1 segment of the ACA & - & $\mathrm{U}$ \\
Aplasia of the posterior communicating artery & - & B \\
Linguofacial trunk & - & $\mathrm{U}$ \\
Labiomental trunk & - & $\mathrm{U}$ \\
\hline
\end{tabular}

ACA — anterior cerebral artery; $\mathrm{B}$ - bilateral; $\mathrm{CB}$ - common carotid artery bifurcation; CCA — common carotid artery; ECA — external carotid artery; ICA — internal carotid artery; IJV — internal jugular vein; STA — superficial temporal artery; StA — superior thyroid artery; U - unilateral; VA — vertebral artery

by patients. The manuscript was tacitly approved by the responsible authorities where the work was carried out.

\section{RESULTS}

Two of the $52(3.8 \%)$ cases presented each the exceptionally rare arterial variation - unilateral MFT. Moreover, in each case different other rare variations were found and are listed in Table 1.

\section{Case 1: Left maxillofacial trunk}

In this first case, the right CCA bifurcation was posterior to the tip of the greater horn of the hyoid bone, at $1.28 \mathrm{~cm}$ deep to the gonial angle (Fig. 1), at the level of the $3^{\text {rd }}$ cervical vertebra. Prior to its bifurcation the CCA was sending off the StA, which originated above the greater horn of the hyoid bone and coursed inferiorly, over that bone. Immediately as the respective ECA left the carotid bifurcation it gave off from its anterior side the LA of which initial segment was coiled and continued inferiorly towards the greater horn. Above the origin of the LA, at the level of the 2 nd cervical vertebra, three major vessels had parapharyngeal posterior kinks, folded into each other: the ECA, ICA and the internal jugular vein (IJV) (Fig. 1). These kinks were at 


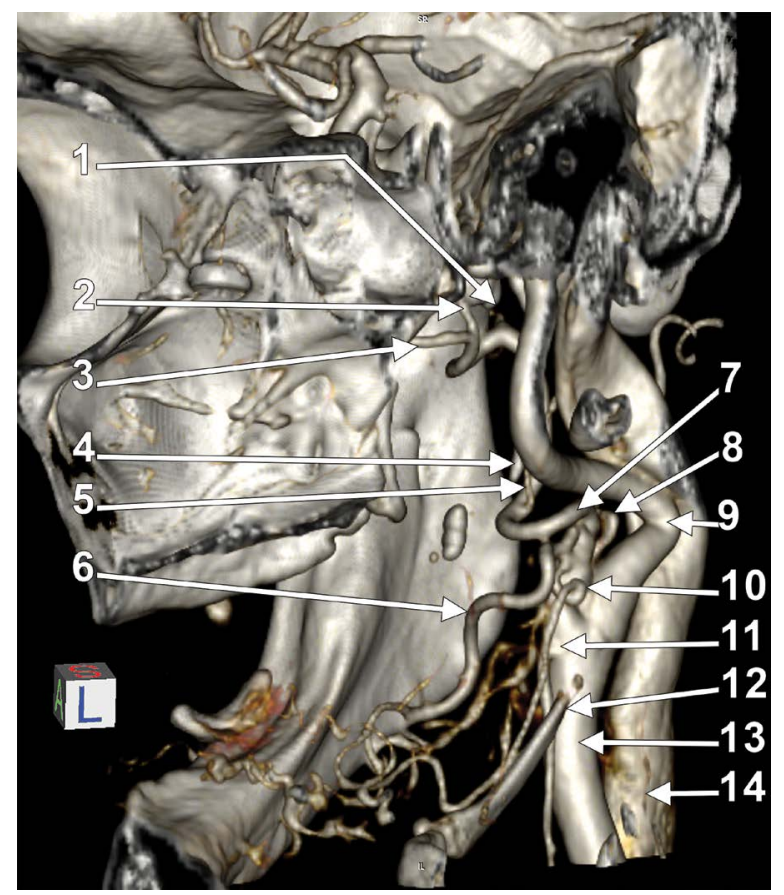

Figure 1. Three dimensional volume renderisation, infero-medial view, right side (case 1); 1 - superficial temporal artery; 2 middle meningeal artery; 3 - maxillary artery; 4 - os stylo-hyale; 5 - posterior auricular artery; 6 - facial artery; 7 - external carotid artery; 8 - occipital artery; 9 - posterior kink of the internal carotid artery; 10 - coiled lingual artery; 11 - origin of the superior thyroid artery; 12 - greater horn of the hyoid bone; 13 common carotid artery; 14 - internal jugular vein.

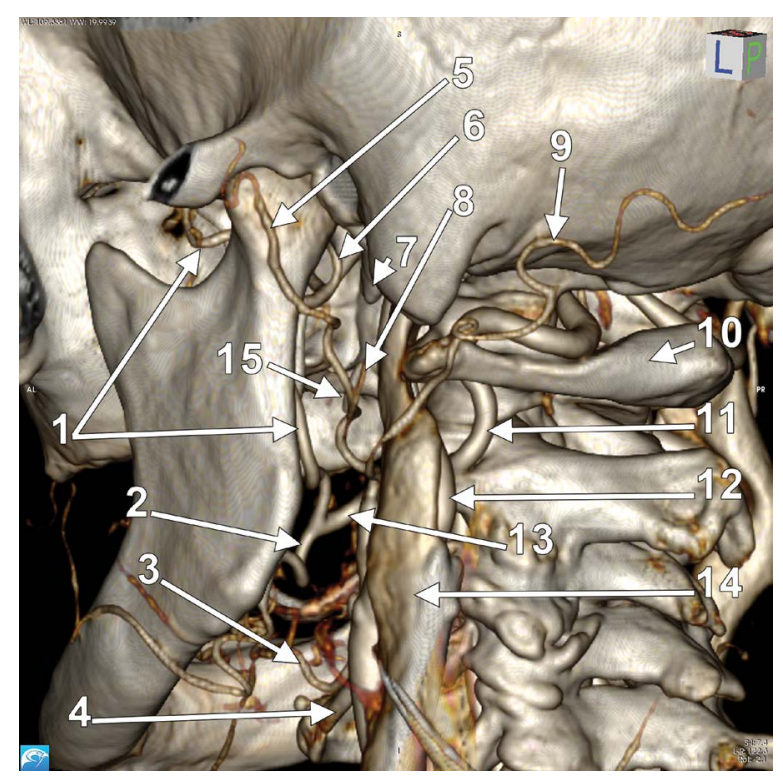

Figure 2. Three dimensional volume renderisation, postero-infero-lateral view, left side. The maxillofacial trunk (case 1); 1 - maxillary artery; 2 - facial artery; 3 - lingual artery; 4 - greater horn of the hyoid bone; 5 - superficial temporal artery; 6 - middle meningeal artery; 7 - os tympano-hyale; 8 - posterior auricular artery; 9 - occipital artery; 10 - atlas vertebra; 11 - vertebral artery; 12 - posterior kink of the internal carotid artery; 13 maxillofacial trunk; 14 — internal jugular vein; 15 — os stylo-hyale.
$1.78 \mathrm{~cm}$ postero-medial to the mandibular ramus, and the kinks of the ICA and IJV were posterior to the frontal plane of the transverse processes of the axis vertebra. From the ECA's posterior kink left a posterior branch - the $O A$, and an anterior one - the FA. The FA originated at $2.18 \mathrm{~cm}$ postero-infero-medially to the mandibular foramen. Then, the FA turned laterally in front of the styloglossus muscle and further descended infero-laterally between the styloglossus and the medial pterygoid to reach the inferior border of the mandible. In that course the FA was placed between the parotid and submandibular glands. Above the anterior loop of the FA was an anterior loop of the ECA which turned laterally also in front of the styloglossus and gave off the PAA. After the PAA emerged the medial side of the ECA it ascended on its inner side. The ECA continued in the retromandibular fossa and bifurcated terminally postero-medial to the mandibular neck into the STA and MA. The MA coursed into the infratemporal fossa deep to the inferior head of the lateral pterygoid muscle.

On the left side (Figs. 2, 3) the CCA bifurcated postero-superiorly to the tip of the respective greater horn of the hyoid bone, at the level of the $3^{\text {rd }}$ cervical vertebra. The StA left the anterior side of the CCA, prior to its bifurcation. At $35 \mathrm{~mm}$ distally from its origin, the left ECA sent off a posterior branch the OA, a medial one - the APA, and an anterior one - the LA. Then the ECA continued vertically for another $59 \mathrm{~mm}$, being located antero-medially to a large posterior kink of the ICA which, in turn, was folded into the medial side of the IJV to get posterior to the frontal plane through the transverse process of the $2^{\text {nd }}$ cervical vertebra. The left ECA divided terminally into the STA and MFT at $1.47 \mathrm{~cm}$ deep to the gonial angle. The STA initially looped anteriorly in the parapharyngeal space, then it continued posteriorly and passed behind the os stylo-hiale to enter the parotid space. At that level the STA gave off the PAA.

The MFT looped anteriorly and then reached laterally the medial pterygoid muscle to bifurcate into an ascending branch - the MA, and a descending one - the FA. The MA ascended posterior to the medial pterygoid muscle, on the medial side of the posterior mandibular border. Above the medial pterygoid muscle the MA reached the inferior head of the lateral pterygoid muscle and continued deep to it with a normal course. 


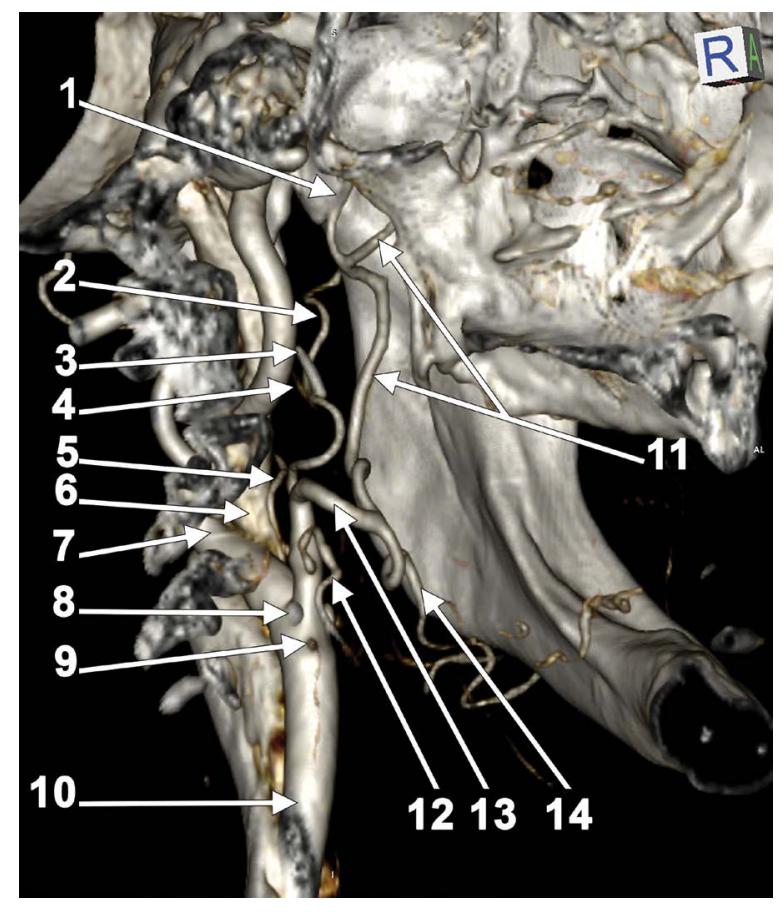

Figure 3. Three dimensional volume renderisation, infero-medial view, left side. The maxillofacial trunk (case 1); 1 - middle meningeal artery; 2 - superficial temporal artery; 3 - os stylo-hyale; 4 - posterior auricular artery; 5 - ascending pharyngeal artery; 6 — internal jugular vein; 7 - posterior kink of the internal carotid artery; 8 - tip of the greater horn of the hyoid bone; 9 - origin of the superior thyroid artery; $10-$ common carotid artery; 11 maxillary artery; 12 - lingual artery; 13 - maxillofacial trunk; 14 - facial artery.

\section{Case 2: Right maxillofacial trunk}

In the second case reported here there were found different unilateral combinations of anatomic variants.

On the left side the CCA had a high terminal bifurcation, which was at mid distance between the greater horn of the hyoid bone and the angle of mandible, at the level of the C3-C4 disc. From that bifurcation left off the StA. From the ECA first left the APA. Then the ECA sent off an anterior linguofacial trunk and the posteriorly directed $O A$, and continued deep to the gonial angle where it gave off the PAA. Then it passed beneath the tip of the styloid process with a medio-lateral course, to continue lateral to it till it reached the postero-lateral side of the neck of mandible (Fig. 4). Here it trifurcated terminally into the STA, MA and TFA (Fig. 4). The OA continued towards the occipital region where it sent off the descending branch. That branch further continued with a thinned and kinked anastomotic arch which joined the left VA into the intervertebral space between the transverse

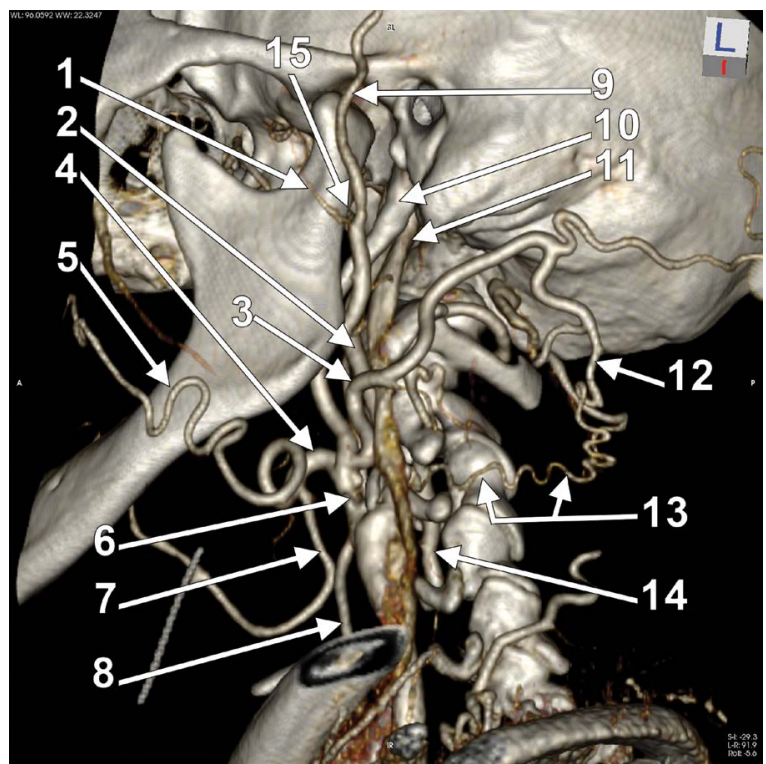

Figure 4. Three dimensional volume renderisation, infero-lateral view, left side (case 2). The occipital-to-vertebral anastomosis. Terminally trifurcated external carotid artery. Linguofacial arterial trunk; 1 - transverse facial artery; 2 - internal carotid artery; 3 - occipital artery; 4 - linguofacial trunk; 5 - facial artery; 6 external carotid artery; 7 - lingual artery; 8 - superior thyroid artery; 9 - superficial temporal artery; 10 - styloid process; 11 - internal jugular vein; 12 - descending branch of the occipital artery; 13 - occipital-to-vertebral arterial anastomosis; $14-$ vertebral artery; 15 - maxillary artery.

processes of the $2^{\text {nd }}$ and $3^{\text {rd }}$ cervical vertebrae (Fig. 4). The VA was further observed in the posterior cranial fossa and was noticed the aplasia of its distal segment (Fig. 5). The left VA was not contributing to the BA. Instead, it continued as left posterior inferior cerebellar artery (Fig. 5). When the circle of Willis was carefully observed it was also noticed the aplasia of the A1 precommunicating segment of the left anterior cerebral artery (ACA) (Fig. 5). The posterior communicating arteries were also absent. Therefore, the respective circle of Willis appeared incompetent.

On the right side the CCA had also a high terminal bifurcation, at the level of the C3-C4 disc. Such as on the opposite side the StA left the CCA bifurcation. Then, from the right ECA were leaving the LA and the OA (Fig. 6). The LA's initial segment was coiled medially to the initial segments of the ECA and ICA. Then, the ECA divided terminally immediately beneath the gonial angle into an anterior MFT and the STA (Fig. 7).

On that side was found an os cerato-hyale located beneath the tip of the styloid process (Fig. 6). The STA crossed posteriorly that os cerato-hyale and 


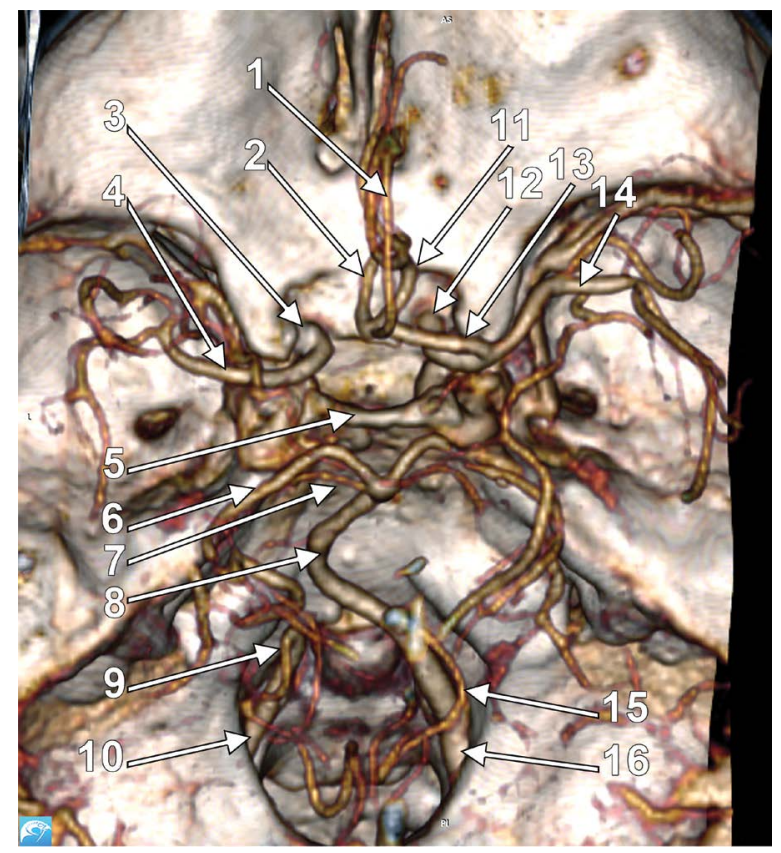

Figure 5. Three dimensional volume renderisation, superior view of the skull base (case 2). Aplasia of the A1 segment of the left cerebral artery. Aplasia of the left distal vertebral artery; 1 - left pericallosal artery; 2 - left anterior cerebral artery; 3 - left internal carotid artery; 4 - left middle cerebral artery; 5 - dorsum sellae; 6 - left posterior cerebral artery; 7 - left superior cerebellar artery; 8 - basilar artery; 9 - left posterior inferior cerebellar artery; 10 - left vertebral artery; 11 - right anterior cerebral artery; 12 - right internal carotid artery; $13-\mathrm{A} 1$ segment of the right anterior cerebral artery; 14 — right middle cerebral artery; 15 - right posterior inferior cerebellar artery; 16 - right vertebral artery.

continued laterally posterior to the mandibular ramus, crossing it at $1.13 \mathrm{~cm}$ above the gonial angle. It sent off the PAA and ascended laterally to the posterior border of the mandibular ramus (Fig. 7), behind the masseter muscle, with the superficial temporal vein on its lateral side. The STA gave off the TFA which ascended on masseter at the level of the mandibular notch and coronoid process. The STA continued laterally to the neck of mandible, covered by the superficial part of the parotid gland. It further ascended over the temporomandibular joint and posterior zygomatic root in the temporal region. The STA divided terminally at pterion into the frontal and parietal branches.

The respective right MFT trifurcated at the tip of the os cerato-hyale into inferior, middle and superior branches (Fig. 6). The inferior one was a glandular submandibular artery. The middle one was an ascending MA. The superior one was the FA. The FA initially descended below the inferior border of the mandible

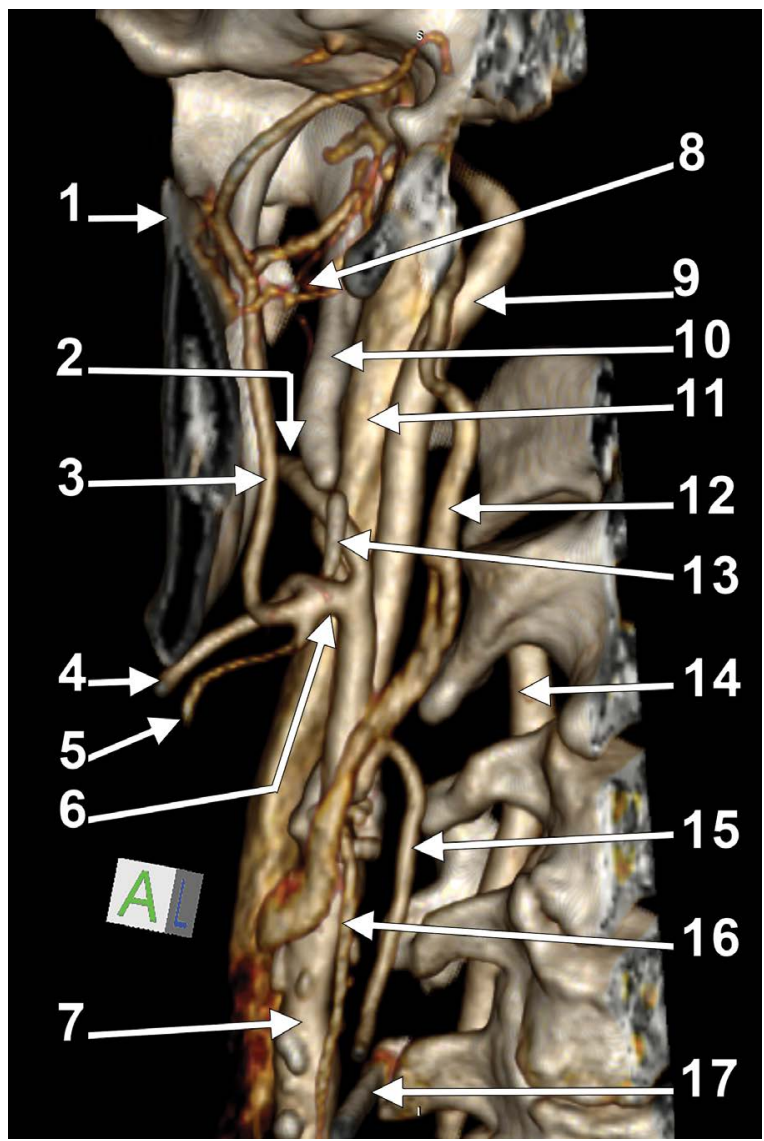

Figure 6. Three dimensional volume renderisation, anterior view, right side. Origin of the maxillofacial trunk (case 2); 1 - coronoid process; 2 - superficial temporal artery; 3 - maxillary artery; 4 - facial artery; 5 - submandibular artery; 6 - maxillofacial trunk; 7 - common carotid artery; 8 - pterygoid plexus; 9 internal carotid artery; 10 - styloid process; 11 - internal jugular vein; 12 - pharyngeal plexus; 13 - os cerato-hyale; 14 vertebral artery; 15 - lingual artery; 16 - superior thyroid artery; 17 - greater horn of the hyoid bone.

then it continued laterally to the body of mandible where it sent off a labiomental trunk (Fig. 8). The MA had an initial ascending course, first being posterior to the medial pterygoid muscle, then passing through it to reach the sulcus colli postero-superior to the mandibular foramen, at the inferior border of the lateral pterygoid muscle. From this level it continued superficially to the lateral pterygoid with a normal antero-superior course, intermingling with veins of the pterygoid plexus (Fig. 7).

When the right ICA was observed above the skull base (Fig. 5) was noticed that the $A 1$ segment of the right $A C A$ was sending the $A 2$ segments of both ACAs. The left pericallosal artery was leaving the A2 segment of the left ACA immediately after this latter originated from the $A 1$ segment of the opposite ACA. 


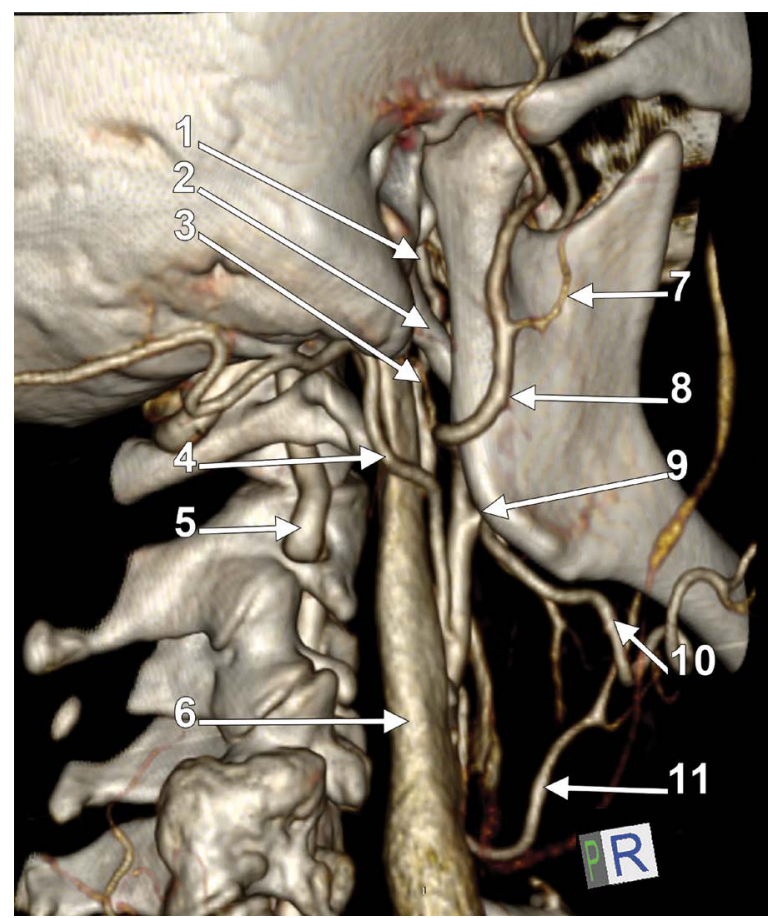

Figure 7. Three dimensional volume renderisation, postero-infero-lateral view, right side. Origin of the maxillofacial trunk (case 2); 1 - internal carotid artery; 2 - styloid process; 3 - posterior auricular artery; 4 - occipital artery; 5 - vertebral artery; 6 internal jugular vein; 7 - transverse facial artery; 8 - superficial temporal artery; 9 - maxillofacial trunk; 10 - facial artery; 11 lingual artery.

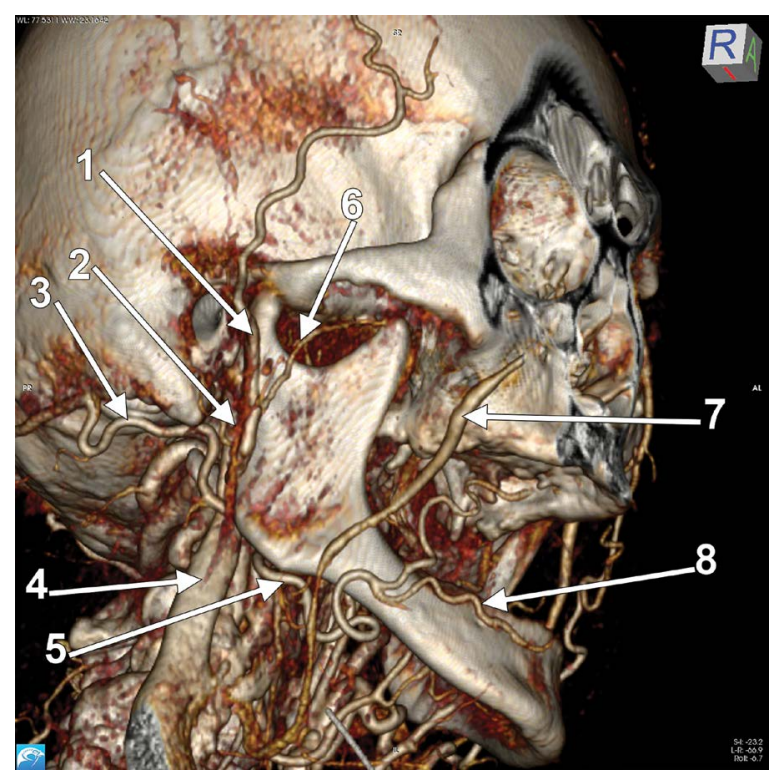

Figure 8. Three dimensional volume renderisation, infero-lateral view, right side (case 2). The labiomental trunk; 1 - superficial temporal artery; 2 - superficial temporal vein; 3 - occipital artery; 4 - internal jugular vein; 5 - facial artery; 6 - transverse facial artery; 7 - facial vein; 8 - labiomental trunk.

\section{DISCUSSION}

\section{The embryonic maxillofacial trunk}

During embryogenesis of the pharyngeal system six paired aortic arches develop bilaterally between primitive ventral and dorsal aortae [21]. The dorsal remnants of the first embryonic aortic arch coalesce with the hyoid artery which emerges the second aortic arch to form the hyostapedial artery [31]. From that latter emerge the primitive supraorbital artery and the embryonic maxillofacial trunk [31]. This embryonic trunk will give rise to infraorbital and mandibular branches and ultimately connects to the ECA, which is a derivative of the ventral aortic system [21,31]. Commonly, the embryonic maxillofacial trunk becomes the definitive MA [25]. The primitive FA arises from the ECA and it could be speculated here that if the ECA origin of the FA glides cranially on the primitive maxillofacial trunk, the adult MFT would result. On other hand, if the primitive maxillofacial trunk, which is a dorsal aortic derivative, fuses with the FA bud, and not with the primitive ECA, it could also result the adult MFT. Nevertheless, if the initial segment of the definitive MA fails to insert on the ECA, it could be replaced by the ascending palatine artery from the FA, as documented in [28].

\section{The maxillofacial trunk in human adult}

The adult MFT appears as the common trunk of ECA origin of the MA and FA. This is different of the embryonic maxillofacial trunk which is the primordium of the definitive MA. Seemingly, Quain (1844) [29] was the first who reported an adult MFT, which was found once in 302 cases.

Pretterklieber et al. [28] reported a case with bilateral MFTs which were dissected in an 88-year-old adult male. The MA had, such as in the 2 cases reported here, two parts: an ascending one, followed by a pterygoid one. Dissections allowed the observation that the ascending part of the MFT-emerged MA ran straight upwards, covered by the posterior margin of the mandibular ramus and by the medial pterygoid muscle; further, the MA pierced that muscle between a tendinous dorsal and a fleshy ventral portion, to continue within the infratemporal fossa. On both sides the pterygoid part of the variant MA coursed deep to the inferior head of the lateral pterygoid muscle. In the present study, while in case 1 the MA ran deep to the lateral pterygoid muscle, in case 2 it was superficial to the respective muscle. 
Different from humans, the MFT is a common phylogenetic trait and is a common finding in lagomorphs with extremely enlarged medial pterygoid and masseter muscles [28]. Therefore, a MFT in man should not be regarded as an atavism but as an ontogenetic adaptation of the arterial anatomy to enlarged masseter and medial pterygoid muscles [28].

\section{The linguofacial trunk}

The linguofacial trunk is a well-known possibility of variation in which the LA and FA could emerge from the ECA [12]. The incidence of the linguofacial trunk has been reported being 7\% [2], 7.5\% [26], 10\% [5], $18 \%[20], 20 \%[7,40]$, or $21 \%$ [24].

\section{The labiomental trunk}

The anatomy of the FA was recently reviewed, being documented that the inferior labial artery it either branches at the cheilion and courses along the vermilion border of the inferior lip, or it branches below the cheilion and courses along the labiomental crease as an horizontal labiomental artery [17], such as in the case 2 reported here. The inferior labial artery and the horizontal labiomental artery are the main arteries used in the lower lip pedicle [18].

\section{Kinked internal carotid arteries}

As Paulsen et al. [27] documented, in most descriptions the cervical part of the ICA runs a straight course to the base of skull. However, in 12/282 preparations (4.2\%) kinks of the ICA were found [27]. These were documented for their relation with the pharyngeal wall, being found that in female patients the ICA kinks come in relation with the pharyngeal wall in $3.33 \%$ of cases [27]. Details on the uni- or bilateral evidence of such kinked ICAs were blurred by the material and methods that were used [27]. In case 1 were found bilaterally symmetrical antero-posterior kinks of the ICAs which were extended posterior to a frontal plane through the transverse processes of the atlas vertebra. Moreover, they were either indenting medially, or displacing posteriorly the adjacent IJV. Such morphological variant brings the ICA and the IJV posterior to the vertebral vessels, this being important in spine and back surgery. As kinking of an artery is the angulation of arterial segments, it is often associated with stenosis [39]. A kinked ICA could be clinically significant and cause cerebral infarction [39]. Few reports detailed previously the IJV extrinsic compression caused by ICA compression [19].

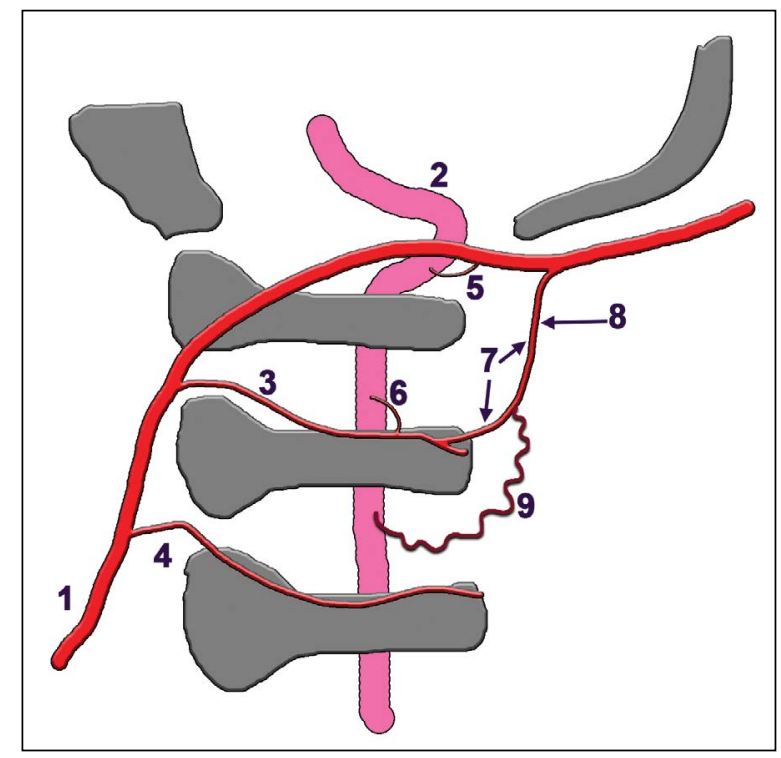

Figure 9. Drawing of a left lateral view updating the occipital-vertebral anastomotic pattern of Lasjaunias et al. [16]; 1 - occipital artery; 2 - vertebral artery; 3 - posterior muscular branch of the $2^{\text {nd }}$ intervertebral space; 4 - posterior muscular branch of the $3^{\text {rd }}$ intervertebral space; 5 - anastomotic channel of the $1^{\text {st }}$ (atlantooccipital) space; 6 - anastomotic channel of the $2^{\text {nd }}$ space; 7 - posterior arch of Lasjaunias; 8 - descending branch of the occipital artery (Nomina Anatomica); 9 - anastomotic channel of the $3^{\text {rd }}$ space (case 2).

The IJV stenosis is characterized by a series of non-specific symptoms determined by blood flow obstruction [19].

\section{Incompetent circle of Willis}

As in case 2 the $A 1$ segment of the left anterior cerebral artery, as well as both, left and right, posterior communicating arteries were also absent, the circle of Willis was regarded as an incompetent one. To that unfavourable anatomical disposition was added the distal aplasia of the left VA (Fig. 9).

\section{Aplasia of the A1 segment of the anterior cerebral artery and bilateral aplasia of the posterior communicating artery}

The aplasia of the A1 segment of the left anterior cerebral artery was found in case 2 . Thus both distal parts of the anterior cerebral arteries were supplied from the contralateral ICA. This is a rare finding, but the most frequently observed variation of the anterior cerebral artery [37]. Lippert and Pabst [20] indicated this variant to occur in $10 \%$ of cases, Carels et al. [6] found it in $10.5 \%$, but Uchino et al. (2006) [37] observed it in just $5.6 \%$ of cases. 
Lippert and Pabst [20] also indicated an incidence of $10 \%$ of the bilateral aplasia or hypoplasia of both posterior communicating arteries. The bilateral posterior communicating artery atresia was listed as a variation in the configuration of the circle of Willis by Jinkins [14]. The unilateral aplasia of the posterior communicating artery was found in $3.5 \%$ of cases [9]. Alpers et al. [1] reported a prevalence of $0.6 \%$ of the unilateral absence of the posterior communicating artery. Saeki and Rhoton [33] credited Alpers et al. [1] for the incidence of the absent posterior communicating but in "Bergman's Comprehensive Encyclopedia of Human Anatomic Variation" [4] this anatomic variation was attributed to Saeki and Rhoton [33]. As it appears, in Bergman's Encyclopedia the possible bilateral absence of the posterior communicating arteries was not documented.

\section{Distal aplasia of the vertebral artery}

Interestingly, on the side with the occipital-vertebral anastomotic channel (case 2) the distal part of that left VA was aplastic, thus it was not contributing to the formation of the BA, but it ended supplying the posterior inferior cerebellar artery. Such a unilateral aplastic distal VA was reported with an incidence of $4.6 \%$ in asymptomatic persons by use of magnetic resonance imaging, while it has been reported as $0.2 \%$ of cases after use of cerebral angiography [23].

\section{The occipital-vertebral arterial anastomosis}

In the 4-5 mm embryos, a pair of neural arteries supply the hindbrain and anastomose with the ICA system through trigeminal, otic, hypoglossal and proatlantal arteries [8]. These are ventro-dorsal anastomotic arteries or cervical somatic arteries [16]. The proatlantal (cervical somatic) arteries persist until the VAs develop [8]. Two types of proatlantal arteries are described: type 1 , when the proatlantal artery arises from the ICA and courses above the atlas vertebra to enter the foramen magnum and join the VA, and type 2, which leaves the ECA and joins the VA outside the skull [8]. Different possibilities of regression of the proatlantal arteries determine the variation of the OA origin, either from the ECA, or from the ICA, or from the VA [16, 36, 38].

In the present study was found, among other variations, an anastomotic channel between the descending branch of the $O A$ and the VA in the $3^{\text {rd }}$ intervertebral space (C2-C3 space). This should not be unusual, as in the anatomical and neuroradio- logical literature is admitted that the OA and VA are anastomosed, usually by muscular anastomotic channels [16].

According to Lasjaunias et al. [16], from the ascending (cervico-occipital) portion of the OA two posterior muscular branches arise and project in the $2^{\text {nd }}$ and $3^{\text {rd }}$ intervertebral spaces, respectively. The branch of the $2^{\text {nd }}$ space anastomoses with the VA by an anastomotic channel of the $2^{\text {nd }}$ space [16]. Further, from the horizontal (occipital) portion of the $\mathrm{OA}$ arise: (a) a direct anastomotic channel of $1^{\text {st }}$ space, which anastomoses with the VA in that atlantooccipital space and (b) a posterior arch (descending branch) that anastomoses with the anastomotic channel of the $2^{\text {nd }}$ space.

Therefore, the anastomotic channel that was found here uniting the descending branch of the $O A$ with the VA in the $3^{\text {rd }}$ space appears as a novel finding to be added to the morphological pattern that was suggested by Lasjaunias et al. [16] (Fig. 9).

If the occipital-vertebral anastomotic channel of the $3^{\text {rd }}$ intervertebral space is regarded as a part of a general arterial picture (Fig. 10) it appears that it could play a certain role in supplying the ipsilateral middle cerebral artery with blood from the VA, thus it compensates the ipsilateral absent posterior communicating artery. However, on the opposite side the arterial anatomy indicates that the VA supplies both posterior cerebral arteries and the ICA supplies the ipsilateral middle and anterior cerebral arteries, as well as the contralateral anterior cerebral one.

Richter [30] found in $25 / 30$ cases segmental branches from the VA to the muscles of the neck, which supports the theory of Lasjaunias et al. [16]. Richter [30] observed filling of the OA that occurred once during vertebral angiography. Additionally he observed in 2 cases of ICA thrombosis the possibility of a compensatory occipital-vertebral flow [30]. In such a case with ICA thrombosis, Richter [30] found multiple small occipital-vertebral connections [10]. Schechter [34] observed in a retrospective study of 1000 cerebral angiograms just 8 cases with occipital-vertebral anastomosis. This author demonstrated on angiograms small anastomotic pathways linking the vertebral system with the descending branch of the OA and discussed they can function in either direction, carotid-to-vertebral or vertebral-to-carotid [34]. Occipital-vertebral anastomoses built-up by muscular branches of the $2^{\text {nd }}$ and $3^{\text {rd }}$ intervertebral space ensured an ipsilateral ECA supply of the cer- 


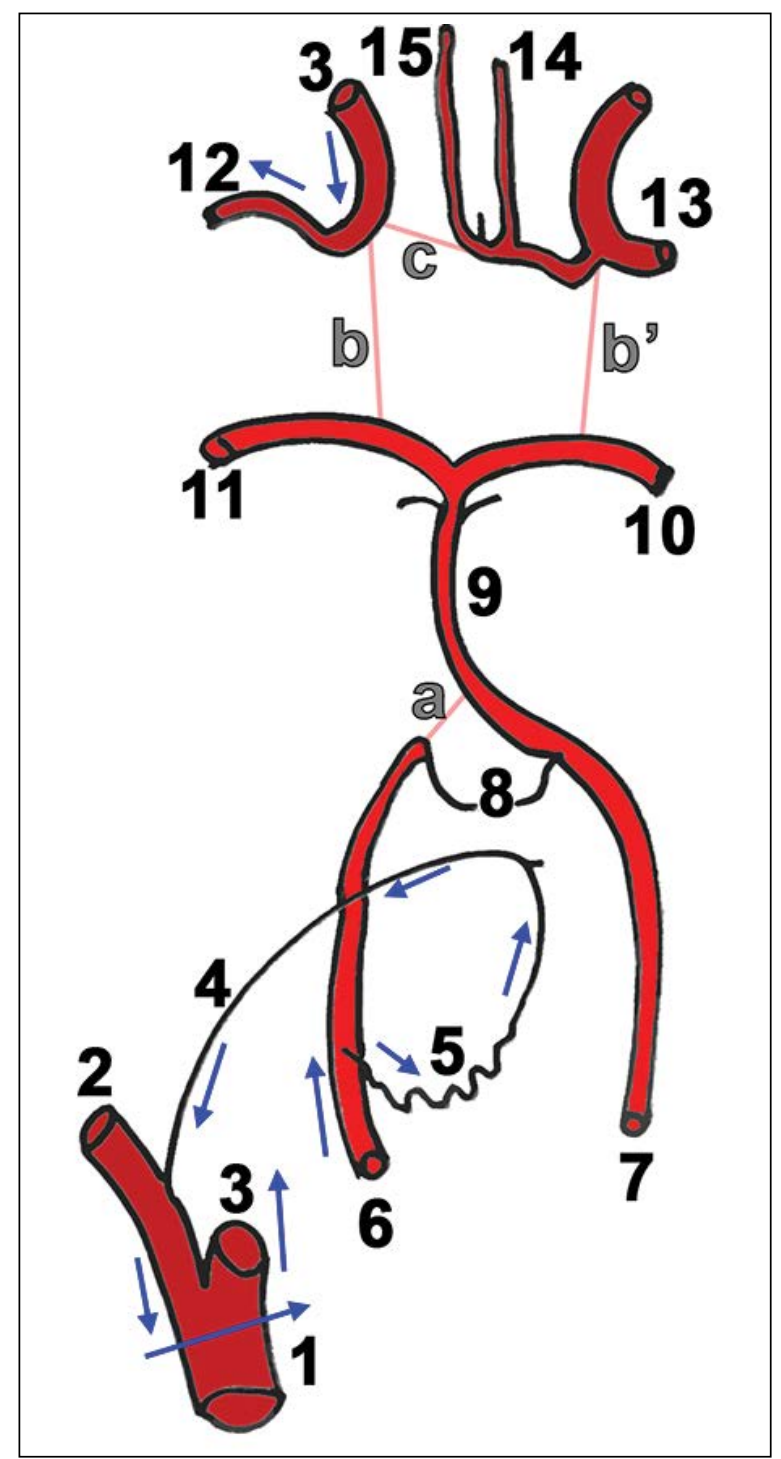

Figure 10. Diagram of the arterial variation (superior view) in case 2. The ipsilateral vertebral-to-middle cerebral artery pathway is indicated with arrows; 1 - left common carotid artery; 2 - left external carotid artery; 3 - left internal carotid artery; 4 - left occipital artery; 5 - occipital-vertebral anastomotic channel of the $3^{\text {rd }}$ intervertebral space; 6 — left vertebral artery; 7 - right vertebral artery; 8 - posterior inferior cerebellar arteries; 9 - basilar artery; 10 - right posterior cerebral artery; 11 — left posterior cerebral artery; 12 - left middle cerebral artery; 13 - right middle cerebral artery; 14 - right anterior cerebral artery; 15 — left anterior cerebral artery; thin lines indicate the aplastic arteries: a — distal left vertebral artery; $b, b^{\prime}$ - posterior communicating arteries; $c$ - left A1 segment of the anterior cerebral artery.

ebral circulation in a case with occluded ICA [13]. The anastomotic channel of the $3^{\text {rd }}$ space was also tortuous, such as in the present report.

Anastomoses of the carotid and vertebrobasilar systems exist or become apparent in different pathological conditions (occlusions, arteriovenous malformations) [13]. The possibility for the occipital-verte- bral anastomoses being constitutive was supported by a series of four cases with such direct anastomoses in the $1^{\text {st }}$ (atlantooccipital space), when just two of these were associated with VA occlusion, the other two being not related neither to ECA, nor to VA occlusion [35]. Rarely, the occipital-vertebral anastomosis is symptomatic (syncope, vertebrobasilar insufficiency) due to a vertebral steal phenomenon through the anastomotic channel [11]. The occipital-vertebral anastomoses are infrequently visualised on angiographies, although they are not uncommon [22]. In the $2^{\text {nd }}$ case reported here the occipital-vertebral anastomosis was seemingly of benefit to compensate the aplasia of different arterial suppliers of the circle of Willis.

\section{CONCLUSIONS}

The arterial anatomical variants of the head and neck should be carefully documented prior to specific surgical and interventional procedures, as well as for understanding the compensatory anatomical pathways of circulatory insufficiencies.

\section{Conflict of interest: None declared}

\section{REFERENCES}

1. Alpers BJ, Berry RG, Paddison RM. Anatomical studies of the circle of Willis in normal brain. AMA Arch Neurol Psychiatry. 1959; 81(4): 409-418, doi: 10.1001/archneurpsyc.1959.02340160007002, indexed in Pubmed: 13636509.

2. Anangwe D, Saidi H, Ogeng'o J, et al. Anatomical variations of the carotid arteries in adult Kenyans. East Afr Med J. 2008; 85(5): 244-247, doi: 10.4314/eamj. v85i5.9619, indexed in Pubmed: 18814535.

3. Bergman RA, Afifi AK, Miyauchi R. Illustrated encyclopedia of human anatomic variation: Opus II: Cardiovascular system: Arteries: Head, neck, and thorax. Maxillary artery. 2013. https://www.anatomyatlases.org/AnatomicVariants/ Cardiovascular/Text/Arteries/Maxillary.shtml.

4. Bergman RA, Tubbs RS, Shoja MM, Loukas M. Bergman's comprehensive encyclopedia of human anatomic variation. John Wiley \& Sons, Hoboken, New Jersey 2016.

5. Cappabianca S, Scuotto A, laselli F, et al. Computed tomography and magnetic resonance angiography in the evaluation of aberrant origin of the external carotid artery branches. Surg Radiol Anat. 2012; 34(5): 393-399, doi: 10.1007/ s00276-011-0926-3, indexed in Pubmed: 22215429.

6. Carels K, Cornelissen SA, Robben D, et al. Smaller caliber of the internal carotid artery in patients with ipsilateral aplasia of the $\mathrm{A} 1$ segment of the anterior cerebral artery: a study with CTA. Acta Neurol Belg. 2018; 118(2): 297-302, doi: 10.1007/s13760-018-0935-7, indexed in Pubmed: 29721852.

7. Devadas D, Pillay M, Sukumaran TT. A cadaveric study on variations in branching pattern of external carotid 
artery. Anat Cell Biol. 2018; 51(4): 225-231, doi: 10.5115/ acb.2018.51.4.225, indexed in Pubmed: 30637155.

8. Gumus T, Onal B, Ilgit ET. Bilateral persistence of type 1 proatlantal arteries: Report of a case and review of the literature. AJNR Am J Neuroradiol. 2004; 25: 1622-1624, indexed in Pubmed: 15502152.

9. Gunnal SA, Farooqui MS, Wabale RN. Anatomical variability of the posterior communicating artery. Asian J Neurosurg. 2018; 13(2): 363-369, doi: 10.4103/ajns. AJNS 152_16, indexed in Pubmed: 29682035.

10. Hackett $E R$, Wilson $C B$. Congenital external carotid-vertebral anastomosis. A case report. Am J Roentgenol Radium Ther Nucl Med. 1968; 104(1): 86-89, doi: 10.2214/ ajr.104.1.86, indexed in Pubmed: 5672781.

11. Harada J, Kuwayama N, Nishijima M, et al. Symptomatic occipital-vertebral anastomosis - a case report. Interv Neuroradiol. 2000; 6(4): 317-320, doi: 10.1177/159101990000600406, indexed in Pubmed: 20667210.

12. Herrera-Núñez M, Menchaca-Gutiérrez JL, Pinales-Razo R, et al. Origin variations of the superior thyroid, lingual, and facial arteries: a computed tomography angiography study. Surg Radiol Anat. 2020; 42(9): 1085-1093, doi: 10.1007/ s00276-020-02507-6, indexed in Pubmed: 32488410.

13. Holodny Al. Supply of the unilateral circulation of the brain by an occipital artery anastomosis - a case report. Angiology. 2005; 56(1): 93-95, doi: 10.1177/000331970505600113, indexed in Pubmed: 15678262.

14. Jinkins JR. Atlas of neuroradiologic embryology, anatomy, and variants. Lippincott Williams \& Wilkins, Philadelphia 2000.

15. Krmpotić-Nemanić J. Anatomie, Variationen und Mißbildungen der Gefäße im Kopf- und Halsbereich (Erläuterungen zum Referat). Archives Of Oto-Rhino-Laryngology. 1978; 219(2): 285-305, doi: 10.1007/bf00463786.

16. Lasjaunias $P$, Théron J, Moret J. The occipital artery. Anatomy - normal arteriographic aspects - embryological significance. Neuroradiology. 1978; 15(1): 31-37, doi: 10.1007/BF00327443, indexed in Pubmed: 643171.

17. Lee HJ, Won SY, O J, et al. The facial artery: a comprehensive anatomical review. Clin Anat. 2018; 31(1): 99-108, doi: 10.1002/ca.23007, indexed in Pubmed: 29086435.

18. Lee $\mathrm{SH}$, Lee HJ, Kim YS, et al. What is the difference between the inferior labial artery and the horizontal labiomental artery? Surg Radiol Anat. 2015; 37(8): 947-953, doi: 10.1007/ s00276-015-1447-2, indexed in Pubmed: 25724940.

19. Li M, Su C, Fan C, et al. Internal jugular vein stenosis induced by tortuous internal carotid artery compression: two case reports and literature review. J Int Med Res. 2019; 47(8): 3926-3933, doi: 10.1177/0300060519860678, indexed in Pubmed: 31304848.

20. Lippert $H$, Pabst R. Arterial variations in man: Classification and frequency. Springer 1985.

21. McEachen JC, Obrzut M, Bokhari SJ. A rare combination of carotid artery congenital abnormalities: understanding the embryology and clinical associations. Emerg Radiol. 2009; 16(5): 411-414, doi: 10.1007/s10140-008-0756-8, indexed in Pubmed: 18682997.

22. Miyachi S, Negoro M, Sugita K. The occipital-vertebral anastomosis as a collateral pathway: Hemodynamic patterns-case report. Surg Neurol. 1989; 32(5): 350-355, doi: 10.1016/0090-3019(89)90138-9.

23. Morimoto $K$, Nagahata $M$, Ono $S$, et al. Incidence of unilateral distal vertebral artery aplasia: evaluation by combining basiparallel anatomic scanning-magnetic resonance imaging (BPAS-MRI) and magnetic resonance angiography. Jpn J Radiol. 2009; 27(3): 151-155, doi: 10.1007/s11604008-0313-0, indexed in Pubmed: 19412683.
24. Natsis K, Raikos A, Foundos I, et al. Superior thyroid artery origin in Caucasian Greeks: A new classification proposal and review of the literature. Clin Anat. 2011; 24(6): 699-705, doi: 10.1002/ca.21181, indexed in Pubmed: 21438023.

25. Osborn AG. Diagnostic cerebral angiography. 2nd ed. Lippincott Williams \& Wilkins, Philadelphia, PA 1999.

26. Ozgur Z, Govsa F, Ozgur T. Assessment of origin characteristics of the front branches of the external carotid artery. J Craniofac Surg. 2008; 19(4): 1159-1166, doi: 10.1097/ SCS.0b013e3180690252, indexed in Pubmed: 18650752.

27. Paulsen F, Tillmann B, Christofides $C$, et al. Curving and looping of the internal carotid artery in relation to the pharynx: frequency, embryology and clinical implications. J Anat. 2000; 197 (Pt 3): 373-381, doi: 10.1046/j.14697580.2000.19730373.x, indexed in Pubmed: 11117624.

28. Pretterklieber ML, Krammer EB, Mayr R. A bilateral maxillofacial trunk in man: an extraordinary anomaly of the carotid system of arteries. Acta Anat (Basel). 1991; 141(3): 206-211, doi: 10.1159/000147123, indexed in Pubmed: 1755281.

29. Quain R. The anatomy of the arteries of the human body. Taylor and Walton, London 1844.

30. Richter HR. Collaterals between the external carotid artery and the vertebral artery in cases of thrombosis of the internal carotid artery. Acta Radiol. 1953; 40(2-3): 108-112, doi: 10.3109/00016925309176574, indexed in Pubmed: 13114009.

31. Rusu MC, Măru N, Rădoi PM, et al. Trifurcated external carotid artery and complete gamma-loop of its maxillary branch. Surg Radiol Anat. 2019; 41(2): 231-234, doi: 10.1007/ s00276-018-2142-x, indexed in Pubmed: 30483866.

32. Rusu MC, Vasilescu A, Nimigean V. A rare anatomic variant: the lateral position of the external carotid artery. Int J Oral Maxillofac Surg. 2006; 35(11): 1066-1067, doi: 10.1016/j. ijom.2006.04.001, indexed in Pubmed: 16828540.

33. Saeki N, Rhoton AL. Microsurgical anatomy of the upper basilar artery and the posterior circle of Willis. J Neurosurg. 1977; 46(5): 563-578, doi: 10.3171/jns.1977.46.5.0563, indexed in Pubmed: 845644.

34. Schechter MM. The occipital-vertebral anastomosis. J Neurosurg. 1964; 21: 758-762, doi: 10.3171/ jns.1964.21.9.0758, indexed in Pubmed: 14210007.

35. Suzuki S, Kuwabara Y, Karasawa S. [The developmental mechanism of occipital-vertebral anastomosis (author's transl)]. No To Shinkei. 1980; 32: 69-79, indexed in Pubmed: 7356852.

36. Tanaka $\mathrm{Y}$, Hara $\mathrm{H}$, Momose $\mathrm{G}$, et al. Proatlantal intersegmental artery and trigeminal artery associated with an aneurysm. Case report. J Neurosurg. 1983; 59(3): 520-523, doi: 10.3171/jns.1983.59.3.0520, indexed in Pubmed: 6886766.

37. Uchino A, Nomiyama K, Takase $Y$, et al. Anterior cerebral artery variations detected by MR angiography. Neuroradiology. 2006; 48(9): 647-652, doi: 10.1007/s00234-0060110-3, indexed in Pubmed: 16786350.

38. Uchino A, Saito N, Mizukoshi W, et al. Anomalous origin of the occipital artery diagnosed by magnetic resonance angiography. Neuroradiology. 2011; 53(11): 853-857, doi: 10.1007/ s00234-010-0825-z, indexed in Pubmed: 21174081.

39. Vannix R, Joergenson EJ, Carter R. Kinking of the internal carotid artery. Am J Surg. 1977; 134(1): 82-89, doi: 10.1016/0002-9610(77)90288-4.

40. Zümre $O$, Salbacak A, Ciçekcibaşi $A E$, et al. Investigation of the bifurcation level of the common carotid artery and variations of the branches of the external carotid artery in human fetuses. Ann Anat. 2005; 187(4): 361-369, doi: 10.1016/j. aanat.2005.03.007, indexed in Pubmed: 16163849. 